\title{
Qualitative and Quantitative Evaluation of Total flavonoids Extracted from Mentha arvnesis Aerial Parts

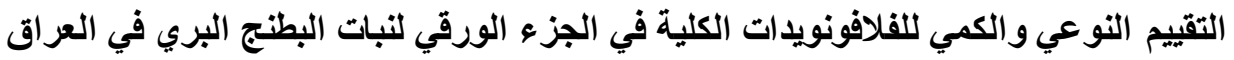

Muna Abd Mutar

Zainab Yaseen Mohammed Hasan*

College of Education for Girls/ Anbar University

"Biotechnology Research Center/Al-Nahrain University

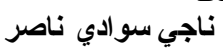

Najy swady Naser

منى عبد مطر

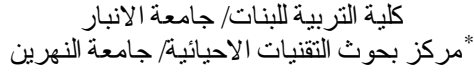

munamutter@gmail.com

\begin{abstract}
Mentha arvnesis is an important medicinal plant that contains many groups of secondary metabolites that have extensive biological activity. The flavonoids were extracted from the aerial parts of the mature plant by using reflex extraction, and the aglycan fraction was isolated with ethyl acetate. The flavonoids of the extract were detected qualitatively with TLC technique. The total amount of flavonoids derived from the plant was estimated using a colorimetric method and the total value was calculated using the straight line equation of the standard flavonoid curve (Rutin). The plant was found to be rich in flavonoids, especially rutin, quarrecetin, kaempferol, luteolin and low concentration of coumarin. Total flavonoids were about $0.78 \mathrm{mg}$ for each gm. powdered aerial parts.
\end{abstract}

Key words: arvensis, areal parts, TLC, Rutin

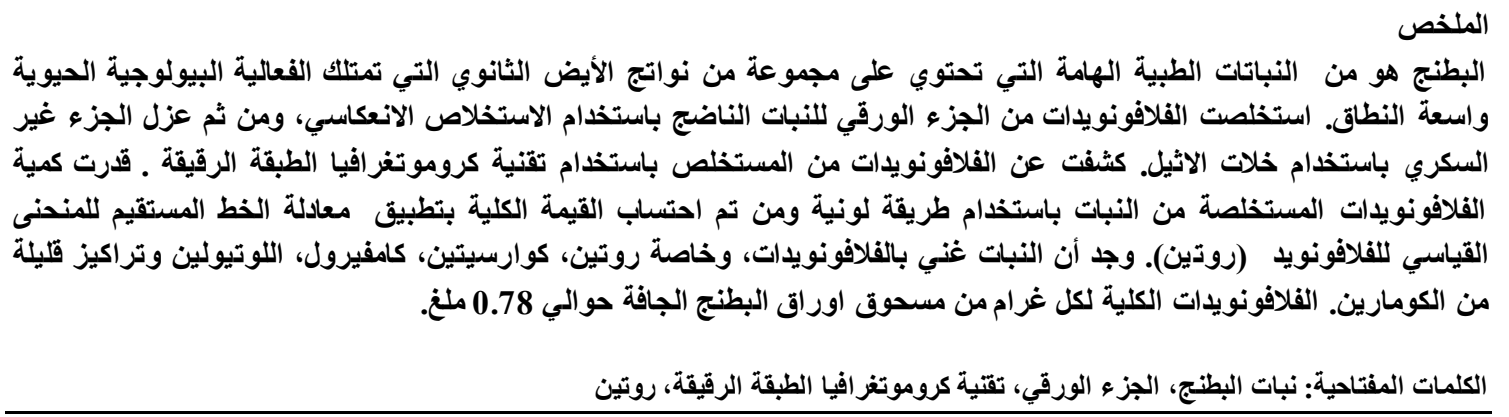

Introduction

Mentha arvnesis the perennial herbaceous plants of the mints genus belonging to the lamiaesea species have been found in different parts of Europe, Asia and North America [1]. M. arvnesis is characterized by its special character. Plant height ranges from $10-60 \mathrm{~cm}$. Green leaves grow around the leg in the form of reverse pairs. These leaves are serrated $2-6.5 \mathrm{~cm}$ long. The leaves have a strong fragrance. Flowers are colored pale Purple and can see some colors in sub-species that grow as large groups. The color of the stem is differed from brown to green [2]. It grows in the spring and is an evergreen plant with random roots, as is the case in all family types of oral crawling freely under the soil [3] and spread in the fields and wetlands and on the edges of the canals and rivers, so called Iraq water mint but a lot of differences between the wild mint and M. arvnesis in some features such a distinctive taste of the later that does not like mint, when eaten freshly or grounded [4].

M. arvnesis flowers were used as anticonvulsant, gastric pain, carminative and disinfectant since the plant pocsse antimicrobial effect that causes bacterial cell damage [5-6]. Many of the chemical compounds, such as essential oil, alcohol, flavonoids, sugars, alkaloids, saponnines and others, which have protective effect against inflammation [7,8] are extracted from this plant. Many studies have been carried out on this plant in Brazil to evaluate the importance of phenolic compounds for industrial purposes, medicinal and aromatic preparations $[9,10]$. These compounds are not needed by the plant for its growth and reproduction but are believed to have a role in the survival of the plant in its environment such as preventing attacks of insects and for protaction. The production of volatile oils in Human use for several aspects: pharmaceutical, food and industrial and other compounds of the secondary metabolism of plants (unlike the primary metabolites) are used in medicine, currently called alternative medicine 
[11,12]. Human had been observed to cure with herbal medicine because of its ease of access, low expenditure and popular belief that it was safer than chemical drugs $[13,14]$

The current study aimed to identify the flavonoids of the plant quantitatively and qualitatively as one of the secondary metabolites in the plant and the biological effect is attributed to these major secondary metabolites in most recent studies.

\section{Material and Method}

\section{First: Plant collection and Extraction}

Arial parts of plant were collected from the Abu Ghraib / Baghdad-Iraq area and were classified in the Faculty of Agriculture, Anbar University, then samples were taken to the laboratory after cleaning well from suspended soil. They were dried at room temperature $25^{\circ} \mathrm{C}$ and manually grinded, then packaged in sterile containers and kept away from direct light until use.

\section{Second: Extract the total flavonoids from the plant}

About $86 \mathrm{~g}$ of powdered plant samples were placed in a 1 liter glass flask and then added $600 \mathrm{ml}$ distilled water with $(10 \% \mathrm{v} / \mathrm{v}) \mathrm{HCl}$. Reflex extraction was performed for 8 hours continuously to ensure that the cleavage and broken of glycoside linkage of the flavonoids and the aglycon part was obtained. The plant extract was Filtered and cooled. The aglycan portion that is the biologic active part of flavonoids is extracted by an organic solvent such as ethyl acetate by adding $50 \mathrm{~mL}$ per each $50 \mathrm{~mL}$ extract and repeated three times using a separating funnel. The acetate layer is collected in the separating funnel again and an equal amount of distilled water is added to remove $\mathrm{HCl}$ residues used in extraction. The acetate layer is then dried using rotary evaporator at $45^{\circ} \mathrm{C}$. The output is saved to complete the rest of the analys is [15].

\section{Third: Phytochemical tests were done according to [16]}

For the purpose of the tests, $10 \mathrm{~g}$ of dried powdered plant macerated in $100 \mathrm{ml}$ of $75 \%$ ethanol for overnight. Then filtered and the concentrated filtrate was identified for the plant chemical components.

\section{A. Detection of tannins tests}

Few drops of the $3 \%$ solution ferric chloride in distill water were added extract of. A greenish blue color indicates the presence of tannins.

\section{B. Detection of glycosides}

$1 \mathrm{~mL}$ of the plant extract was mixed with $2 \mathrm{ml}$ of the benedict reagent, then the mixture placed in boiling bath for 5 minutes and left to cool. The red deposit indicated a presence of this group.

\section{Detection of alkaloids (Dragangroff test)}

Weigh about $60 \mathrm{mg}$ of bismuth subnitrate and dissolved in $0.2 \mathrm{ml} \mathrm{HCL}$, this is solution. A Solution B contains $600 \mathrm{mg}$ potassium iodide in $1 \mathrm{ml}$ distell water

We mix the solution $[\mathrm{A}+\mathrm{B}]$ and then add the plant extract; an orange to brown color will indicate the presence of alkaloids.

\section{Detection of the saponines}

The detection process will be proceeding by shaking the plant extract well. Formation of foam at the top will indicate presence of saponines.

\section{E. Detection of flavonoids}

i- (alkaline reagent test) by using Sodium hydroxide solution is mixed with few amount plant extract solution and left, a yellow color is obtained in presence of flavonoids.

ii-( Acidic test using a sulfuric acid ): formation of orange-reddish color indicated the presence of flavonoids .

\section{F. Detection of Polyphenolic compounds}

Using $1 \%$ ferric chloride solution to the plant extract solution a brown deposition will formed.

Fourth: Determination of Total Flavonoids.

\section{Qualitative assay}

A stock solution from the extracted total flavonoids was prepared by dissolving $0.150 \mathrm{gm}$. Residue in 5 $\mathrm{ml}$ of $50 \%$ ethanol. A standard rutin, querecetin, and luteolin solutions were prepared in $50 \%$ ethanol also. Thin layer chromatography (TLC) was carried out using a silica coated silica60 plate with a thickness of $0.1 \mathrm{~mm}$ which represents the stationary phase in the chromatography separation process. As for the mobile phase, different phases were used as shown in Table (1) 
Table (1): shows the ratio the mobile phase used in the qualitative evaluation of flavonoids

\begin{tabular}{cc}
\hline Mobile Phase numbe & Ratio for Mobile Phase \\
\hline 1 & Toluene: Ethyl acetate :Formic acid $(36: 12: 5)$ \\
3 & Chloroform : Glacial acetic acid : Formic acid $(44: 3.5: 2.5)$ \\
4 & n-Hexane : Ethyl acetate $:$ Glacial acetic acid $(30: 20: 1.5)$ \\
5 & n-Hexane : Ethyl acetate : Glacial acetic acid $(31: 14: 5)$ \\
& n-Butanol : Glacial acetic acid : Distill water $(20: 5: 25)$ \\
\hline
\end{tabular}

The TLC process is applied and the plate is placed in the mobile-saturated chamber as mentioned above. Flavonoids are left to be separated depending on their binding to the stationary-phase and solubility in the mobile phase. When the mobile phase reached about three-quarters of the plate or more, plates were removed and solvent front line was boarded. The type of flavonoids separated can be detected in corresponding to standard flavonoids spots in their distance that called RF value. This value is derived from dividing the distance travelled by each flavonoid in each model phase to the distance traveled by the solvent:

\section{The distance traveled by each flavonoid}

Rf value $=$

\section{Distance traveled by the mobile phase}

Each Flavonoid can be detected separately by the exposure of the silica plate to the UV light as a colored spot. The silica plate is covered with Fluorescent material, which flashes when it binds to the active groups of flavonoids under UV at a wavelength of $254 \mathrm{~nm}$. The result is shown as bright spots under the UV light [17].

\section{Quantitative Assay}

Several rutin standard flavonoid solutions were prepared with concentrations of $(0.15625,0.3125,0.625$, 1.25 and $2.5 \mathrm{mg} / \mathrm{ml}$ ) in $50 \%$ ethanol solution. The following interaction is performed:

About $1 \mathrm{ml}$ of plant total flavonoids extract is transferred to aglass tube, and $1 \mathrm{ml}$ rurin standard solutions of each concentration is placed in separated glass tube. $1 \mathrm{ml}$ of $5 \%$ sodium nitrite solution which dissolved in 50\% ethanol was added to all tubes, then stirred and left in room temperature for 5 minutes, added to each tube $2 \mathrm{ml}$ of aluminum chloride at a concentration of $10 \%$ dissolved in $50 \%$ ethanol. Then the tubes were mix and leave for another 5 minutes at room temperature. Finally, $5 \mathrm{~mL}$ of $1 \mathrm{~N} \mathrm{NaOH}$ solution was added stir the mixture and then read the resulting color with spectrophotometer at 510nm wavelength [19]. A standard curve is then performed between reading absorbance of each standard solution with their known concentration to get the straight line equation and then calculating the concentration of the total amount of flavonoids in extracted plant [18].

\section{Results}

\section{First: Extract the total flavonoids from the plant}

The results indicated that each $86 \mathrm{~g}$ of the grounded aerial plant was produced about $1.3153 \mathrm{~g}$ residues resulting from the extraction and drying process of the rotary evaporator.

\section{Second: Phytochemical investigation}


Table (2): Phyto-chemical investigation of Mentha arvnesis active compounds

\begin{tabular}{ccc}
\hline Active compounds & Name of the detector & Result \\
\hline Alkaloids & Dragandroff & + \\
Flavonoids & Base Alkaline test detection & + \\
Phenols & using NaOH & + \\
The saponnines & Ferric chloride Detector 1\% & + \\
Glycosides and sugars & Formation of foam & + \\
Tannins & Benedict detector & + \\
\hline
\end{tabular}

"Positive results gave the symbol(+)

Third: Determination of total flavonoids

\section{A. Qualitative assay}

Flavonoids were extracted from the plan identified by thin layer chromatography (TLC). Spots were obtained by UV exposure when exposing the plate to a $254 \mathrm{~nm}$ wavelength in comparison with standard flavonoids, Figure (1)

Table (3): flavonoids diagnosed in the Menthe plant and Rf values

\begin{tabular}{cc}
\hline Rutin & (Base line) \\
\hline Quarecetin & 0.43 \\
Luteolin & 0.30 \\
Kaempfrol & 0.49 \\
Flavonoids Mentha arvnesis extracted & All above rates with unknown flavonoids rates \\
\hline
\end{tabular}

Table (4) shows flavonoids and their Rf values of the standard flavonoids identified in plant extract.

Table (4): Diagnosed of rutin and quarstine in the Mentha plant

\begin{tabular}{|c|c|c|c|c|c|c|}
\hline \multirow[b]{2}{*}{ Number } & \multirow[b]{2}{*}{ Flavonoid Types } & \multicolumn{4}{|c|}{ The $R_{f}$ Values in Each Mobole Phase } & \multirow[b]{2}{*}{$\begin{array}{c}\text { Mobile } \\
\text { Phase (5) }\end{array}$} \\
\hline & & $\begin{array}{c}\text { Mobile Phase } \\
\text { (1) }\end{array}$ & $\begin{array}{c}\text { Mobile Phase } \\
\text { (2) }\end{array}$ & $\begin{array}{r}\text { Mobile } \\
\text { Phase (3) }\end{array}$ & $\begin{array}{c}\text { Mobile } \\
\text { Phase (4) }\end{array}$ & \\
\hline 1 & Rutin & (Baseline) & (Baseline) & 0.33 & 0.36 & 0.71 \\
\hline 2 & Querecetin & 0.43 & 0.14 & 0.92 & 0.91 & 0.86 \\
\hline 3 & $\begin{array}{l}\text { The Extracted } \\
\text { Flavonoids }\end{array}$ & \multicolumn{5}{|c|}{ All above flavonoids $R_{f}$ values with another unknown flavonoid spots } \\
\hline
\end{tabular}

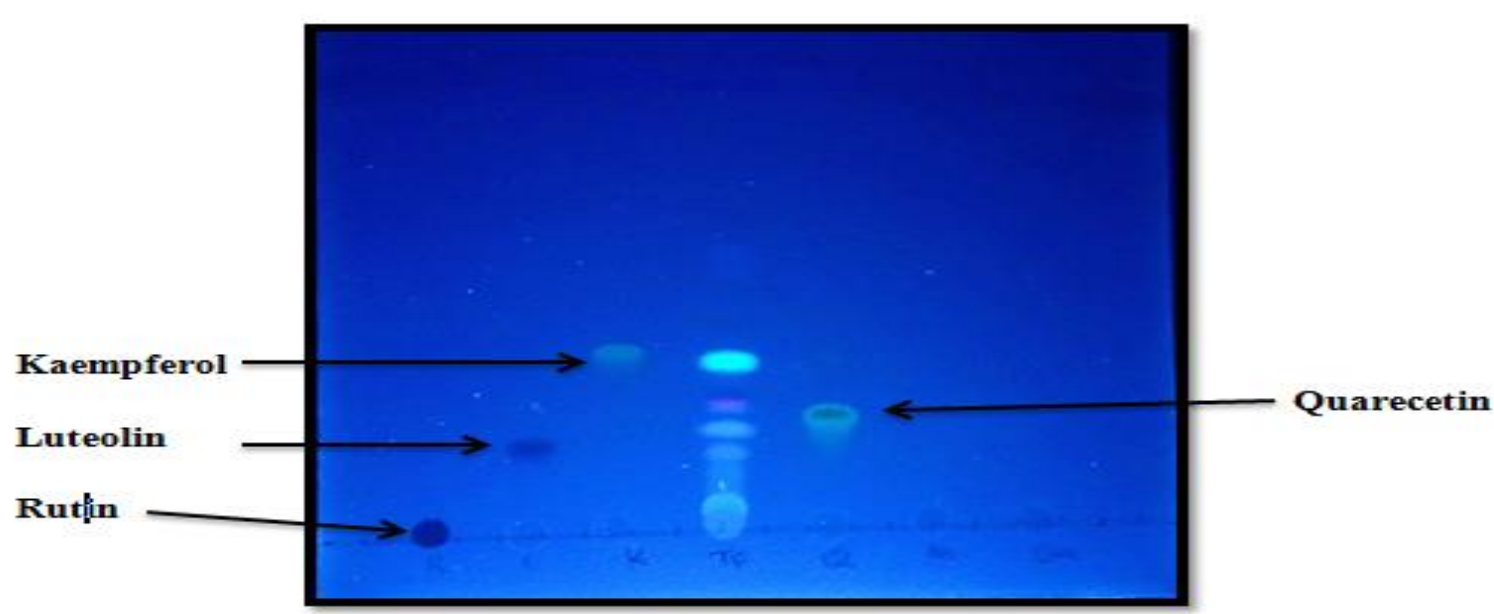

Fig. (1): TLC chromotogram used in the identification of the extracted flavonoids in corresponding to standard solutions ;including $\left(T_{f}\right)$ Total flavonoids extracted from Mentha arvnesis , (K) kaempferol, (L) luteolin (R) rutin, and(Q) Quercetin 


\section{B. Quantitative Assay}

The amount of flavonoids found in the abdominal plant was estimated using the optical spectrometer at $510 \mathrm{~nm}$ depending on the concentration of the standard routine solution Table (3) where the straight line equation is obtained as shown in Figure (2)

Table (5): Absorption values of standard flavonoids Routin at different concentrations and total flavonoids of tubal plant

$\begin{array}{cc}\text { Absorption at } & \text { Rutin standard solution }(\mathbf{m g} / \mathbf{m l}) \\ (510 \mathrm{~nm}) & 0.15625 \\ 0.135 & 0.3125 \\ 0.341 & 0.625 \\ 0.602 & 1.25 \\ 1.003 & 2.5 \\ 2.750 & \text { Total Mentha flavonoids }(\text { double diluted }) \\ 2.0012 & \end{array}$

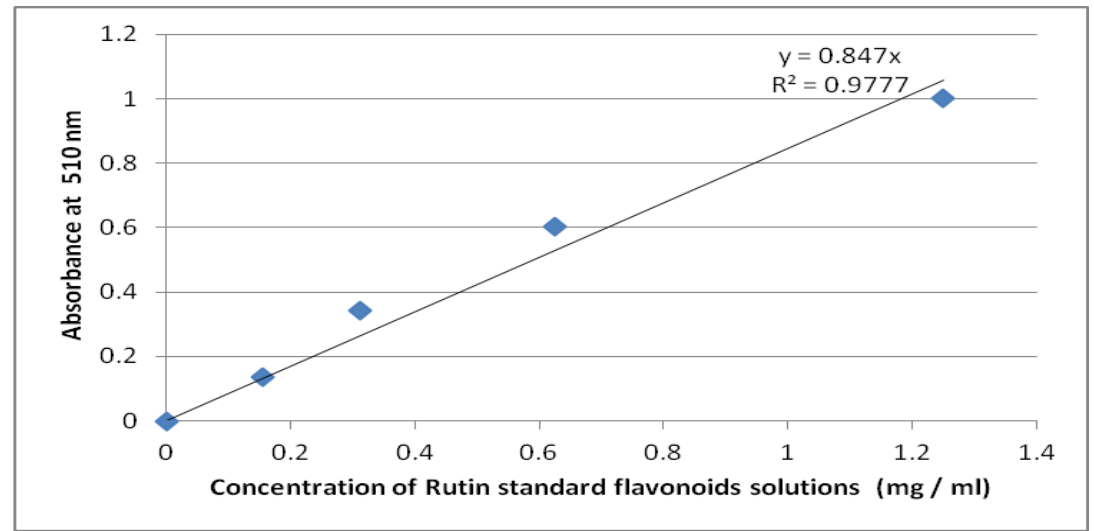

Fig. (2): Rutin standard curve

From the equation of the straight line of the standard flavonoid curve to the Rutin with different concentrations, the concentration of the total flavonoids for the extract of the M. arvnesis is as follows:

$\mathrm{Y}=1.0369 \mathrm{X}_{1}$

$2.0012=1.0369 X_{1}$

$X_{1}=1.94 \mathrm{mg} / \mathrm{ml}$

Since the extract is diluted twice and dissolved in $5 \mathrm{ml}$ in an alcoholic solvent $50 \%$ alcohol, the total concentration of flavonoids per $86 \mathrm{~g}$ of the Mentha arvnesis plant powder is approximately $170 \mathrm{mg}$. Therefore, the total concentration of flavonoids per $1 \mathrm{~g}$ of Mentha arvnesis powder will be:

$170 \mathrm{mg} /(\mathbf{8 6 g})=2 \mathrm{mg}$ (approximation)

Where: $Y=$ absorption; $X=$ concentration $\mathrm{mg} / \mathrm{ml}$.

Discussion

In current study, the quantitative and qualitative value of flavonoids were estimated taking amount of plant aerial parts powdered from Wild Iraqi (Mentha arvensis), this study has shown that the plant is rich in flavonoids, where it has been shown that for every $100 \mathrm{~g}$ of powder aerial parts of the plant contain $200 \mathrm{mg}$. Flavonoids are major secondary metabolites consist of one or more hydroxyl phenolic groups with sugar moiety. Mentha arvnesis plant is a good source of phenolic compounds such as glycosides and flavone, which have a protective effect against inflammation. One study done by (Olli and co 2011) showed that there is a significant effect in preventing or curing the injury due to the presence of Phenolic compounds in the extract of Mentha arvnesis [19].

Total flavonoids of Mentha arvensis in present research were extracted and identified by the TLC technique to qualify and separate this extracted flavonoid in corresponding to standard solution including (Quercetin, kaempferol, luteolin and rutin). All these compounds play a major role in biological effectiveness. Flavonoids are the most important classes of active compounds found in the plant and the most abundant is rutin and Quercetin. Both have multiple bio-efficacy in alternative medicine may be 
used as a treatment in many conditions and as free radical scavenger. In a study carried out on the infusion of a variety of herbs used in Brazil, including botanic plant for the verification of phenolic compounds, including flavonoids as antioxidants and free radicals, showed that the Mentha spp. contains about $3 \mathrm{mg} / \mathrm{g}$ of phenolic compounds using vegetable parts .It was also observed that this batch was statistically significant as an antioxidant [20]. In another study conducted in India on Indian herbs used in Indian foods, it was found that the total flavonoids content in this plant was $1.57 \mathrm{mg} / \mathrm{gm}$ dried leaves [21], while the total flavonoids in the aerial parts of the Iraqi Mentha arvensis was about $2 \mathrm{mg} / \mathrm{g}$, which is very abundant and very rich in flavonoids. Our study also showed that after the chemical tests, the plant contains a percentage other bioactive component such as: volatile oils glycosides, sapponins, alkaloids, tannins and Polyphenolic compounds including flavonoids.

\section{References}

1. Johnson, M., Wesely, E.G., Kaveitha, M., wesely, E.G., Kavitha, M.S. and Uma V. (2011). Antibacterial activity of leaves and inter-nodal callus extracts of menthe arvensis L. Asian pacific journal of tropical medicine, 4(3).p.196-200.

2. Global Healing center. (2016). Tips for growing peppermint (on Line). Houstone,Texas (Accessed 20 ${ }^{\text {th })}$

3. Hussain, A.I., Anwar, F., Nigam, T., Ashraf, M., Gilani, A.H. (2010). Seasonal variation in content, chemical composition and antimicrobial and cytotoxic activities of essential oils from four Mentha species. J.Sci. Food Agric, 90, 1827-1836.

4. Mimeca Dukic, N., Bozin, B. (2008). Mentha L. Species (Lamiaceae) as promising sources of bioactive secondary metabolites. Curr. Pharm. Design, 14, 3141-3150.

5. Lòpez -Lázaro, M. (2009). Distribution and biological activities of the flavonoid luteolin. J. Med. Chem, 31-59.

6. Zang, L., Xu, S.G., Liang, W., Mei, j., Di,Y.Y., Yang, H.H., Wang, Y., Luo,Y.Y. and wang, H.Z. (2015). Antibacterial Activity and mode of Action of menthe arvensis ethanol extract against multidrug - resistant acinetobacter bou,annii. Tropiat journal of pharmaceutical research -14(11). P: 2099-2016.

7. Deepa, G., Aditya, M., Nishta, K., and Thankamani, M. (2012). Comparative analysis of phytochemical profit and anti oxdent activity of some indian culinary Herbs. Reseaily sournal of pharma ceuticel biological and chemical science vol.3, pag, 845-854.

8. Chen, S., Shimada, K., Zhang, W., Hung, G., Crother, T., Arditi, M. I. L. (2010). 17A is Proatherogenic in high- fat diet-induced. J. Immunol. 185, 5619-5627.

9. Moraes-de-Souza, R,A., Oldoni, T.L.C., Regtano-d Arce, M.A.B. and ALencar, S.M. (2008). Antioxidant activity and phenolic composition of herbal Infusions consumed in Brazil CYTA. Journal of Food, .6:1, 41-47.

10. Chadwich, D. j. and whelean, J. (1992) .Secondary metabolites: their function and evolution-wiley interscience, NewYork.

11.Klibenstein, D.J. (2004), secondary metabolites and plant/ environment interaction a view through Arabidopsis thaliana tinged glasses. Plant cell and Environ. 27, 675-684.

12.Rahber, B.M.H. (1988). Antifungal properties of plant leaf decoctions against leaf rust of wheat. Pak. J. Botany., 20, 259-264 .caporale L.H.1995 chemicalcoecology: a view from the pharmacentical industry. Proceedings of the Na USA, 92, 75-82.

13.Ball, E. A. and Charlwood, B.A. (1980). Secondary plant products. (Encyclytedia of plant physiology, vol.8). Berlin-Heidelperg-Newyork: springer verolage.

14. Majed jamous, R., Ali-shtayep, M.S. (2008). Traditianal Arbic Palestinian Harbal Medicine. Biodiversty and Environmental Reasherch center (B E R C). Til, Nablus.

15.Harborne, J.B. (1984). Phytochemical methods, A guide to modern techniques of plant analysis. Second edition, chapman and Hall, London, pp. 169-172.

16.Leland, J., Cseke, Ara, Kirakosyan., Peter, B., Kaufman Sara, L.,Warber James, A. Duke. and Harry, L. Brielmann. (2002). Natural Products from Plants, Second Edition. Boca Ratin: CRC Press

17.Marcica, M.S.,Vesna, R., Mirza, B. and Zelijan, M. (2112). From functional food to Medicinal product system atic appoach in analys is of polyphenolic, from popolis and wine; Nutrition journal, vol. 8. PP. 33.

18. Kato, M., Mizuna, K., Fujimura,T.I., Wama, M., Irie, M., krozier, A., Ashihara, H.H. (1999)."Purification and characterization and of caffeine syntheses from tea leaves". Plant Physiology. Vol. 120(2). pp: 579-86.

19.Olli, S., Liisa, T., Maija, L. and Elise, S. (2011). Corn Mint (Mentha arvensis). Extract diminishes acute chlamydia pneumoniae infection in vitro and in vivo. Journal of Agricultural and Food Chemistr.vol.59, Page 12836-12842. 
20. Moraes-de Souza, R.A., Oldoni, T.L.C., Regitano-d Arce, M.A.B. and Alencar, S.M. (2008). Antioxidant activity and phenolic composition of herbal infusions compound in Brasil, CYTA- Journal of Food, 6:1, 41-47.

21.Deepa, G., Aditya, M., Nishtha, K. and Thankamani, M. (2012). Comparative analysis of phytochemical profile and antioxidant activity of some Indian culinary herbs. Research Journal of Pharmaceutical. Biological and chemical Sciences, vol. 3, Pag.845-854. 